\title{
Revista Agrarian \\ ISSN: 1984-2538 \\ Glicerina bruta melhora o valor nutricional de silagem de milheto colhido em duas idades
}

\section{Crude glycerin improves the nutritional value of millet silage harvested at two ages}

\author{
Samantha Mariana Machado, Eleuza Clarete Junqueira de Sales, João Paulo Sampaio Rigueria, \\ Daniel Ananias de Assis Pires, Ariadne Freitas Silva, Flávio Pinto Monção \\ ${ }^{2}$ Universidade Estadual de Montes Claros, Av. Prof. Rui Braga, S/N - Vila Mauriceia, Montes Claros - MG, \\ 39401-089 Montes Claros, MG
}

Recebido em: 05/10/2018

Aceito em:27/02/2019

Resumo: Objetivou-se avaliar o melhor nível de inclusão de glicerina bruta na ensilagem de milheto colhidos em duas idades de corte e seus efeitos sobre o perfil fermentativo e valor nutricional. Os tratamentos consistiram na adição de glicerina bruta durante a ensilagem de Milheto (BRS 1502) em 5 doses de inclusão na matéria natural $(0,5,10,15$ e $20 \%$ ) e duas idades de corte do milheto (60 e 80 dias) seguindo delineamento em inteiramente casualizados em esquema fatorial $5 \times 2$. A maior média de $\mathrm{pH}$ e nitrogênio amoniacal da silagem de milheto foi verificada no tratamento controle colhido aos 80 dias de idade, sendo o valor de $3.33(P=0.02)$ e $6.09 \%$ do nitrogênio total $(P<0.01)$, respectivamente. Silagem de milheto colhida com 80 dias e aditivada com $20 \%$ de glicerina obteve maior teor de matéria seca $(P<0.01 ; 30,05 \%)$, extrato etéreo $(P<0.01 ; 8.5 \%)$ e nutrientes digestíveis totais $(P=0,01 ; 76.8 \%)$. A colheita da planta de milheto aos 80 dias associada com a utilização de $15 \%$ glicerina bruta na matéria natural durante a ensilagem melhora o perfil fermentativo e as características nutricionais da silagem.

Palavras-chave: aditivos, bioprodutos, composição química, digestibilidade

Abstract: The objective was to evaluate the best level of inclusion of crude glycerin in millet silage harvested at two cutting ages and its effects on the fermentation profile and nutritional value. The treatments consisted of the addition of glycerin during the ensilage millet (BRS 1502) in five inclusion doses in the natural material $(0,5,10,15$ and $20 \%)$ and two cutting ages millet (60 and 80 days) following a completely randomized design in a $5 \times 2$ factorial scheme. The highest mean $\mathrm{pH}$ and ammoniacal nitrogen content of millet silage was observed in the control treatment at 80 days of age, with a mean of $3.33(\mathrm{P}=0.02)$ and $6.09 \%$ of the total nitrogen ( $\mathrm{P}<0.01)$, respectively. Millet silage harvested at 80 days and supplemented with $20 \%$ glycerin obtained higher dry matter content $(\mathrm{P}<0.01 ; 30.05 \%)$, ether extract $(\mathrm{P}=0.01 ; 8.5 \%)$, total digestible nutrients $(\mathrm{P}=0.01 ; 76.8 \%)$. Harvesting of the millet plant at 80 days associated with the use of $15 \%$ crude glycerin in the natural matter during silage improves the fermentation profile and the nutritional characteristics of the silage.

Keywords: additives, bioproducts, chemical composition, digestibility

\section{Introdução}

Em regiões semiáridas, o cultivo de plantas forrageiras produtivas, de ciclo curto e baixa exigência hídrica, tem se tornado uma estratégia consolidada para produção de silagens, principalmente no final da estação chuvosa (Campos et al., 2017). O cultivo de Milheto (Pennisetum glaucum), por exemplo, tem se destacado por atender as exigências dos produtores tanto em produção de massa quanto em eficiência de uso da água.
No entanto, a colheita antecipada com 60 dias após plantio para produção de silagem pode ter como agravante elevado teor de umidade (Dias et al., 2014), o que pode não favorecer uma fermentação adequada como a síntese de ácido lático e/ou acético (Moura et al., 2017).

$\mathrm{O}$ uso de aditivos sequestrantes de umidade pode ser uma alternativa para melhorar o perfil fermentativo e o valor nutricional da silagem produzida. Dentre os diversos aditivos, a glicerina bruta, subproduto da produção de biodiesel, se destaca por apresentar alto teor de 


\section{(2) \\ Revista Agrarian \\ ISSN: $1984-2538$}

matéria seca e extrato etéreo (Kerr et al., 2009). Diversos estudos comprovam a importância nutricional da glicerina bruta para ruminantes (Lee et al., 2011; San Vito et al., 2016; Paiva et al., 2016), mas são escassas pesquisas utilizando esse subproduto na ensilagem de gramíneas tropicais sobre o perfil fermentativo e valor nutricional (Dias et al., 2014).

Sendo assim, objetivou-se avaliar o melhor nível de inclusão de glicerina bruta na ensilagem de milheto colhidos em duas idades de corte e seus efeitos sobre o perfil fermentativo e valor nutricional.

\section{Material e Métodos}

A pesquisa foi conduzida na fazenda experimental da Embrapa Milho e Sorgo localizada no município de Sete Lagoas, Minas Gerais, Brazil (19०27'57' S, 44 14' 48” O). A precipitação anual média é de $1272 \mathrm{~mm}$ com temperatura anual média de $23^{\circ} \mathrm{C}$, umidade relativa do ar em torno de $70,5 \%$ e, segundo a classificação climática de Koppen (1948), o tipo de clima predominante na região é o $\mathrm{Aw}$ (Antunes, 1994).

Os tratamentos consistiram na adição de glicerina bruta durante a ensilagem de Milheto (BRS 1502) em cinco doses de inclusão na matéria natural $(0,5,10,15$ e $20 \%)$ e duas idades de corte do milheto (60 e 80 dias) seguindo delineamento inteiramente casualizado em esquema fatorial $5 \times 2$, sendo cinco doses de glicerina e duas idades de corte.

O plantio foi realizado em 12/02/2016 em área previamente mecanizada. Antes do plantio, vinte amostras de solo foram coletadas a profundidade de $0-20 \mathrm{~cm}$, em zig zag, ao longo da área experimental usando trado holandês. As porções do solo coletados foram misturadas em recipiente de plástico e subamostras foram colhidas para análise química do solo.

$\mathrm{O}$ resultado da análise química foi $\mathrm{o}$ seguinte: $\mathrm{pH}=6,3 ; \mathrm{Ca}^{2+}\left(\mathrm{cmolc} \mathrm{dm}^{-3}\right)=1,6 ; \mathrm{Mg}$ ${ }^{2+}\left(\mathrm{cmolc} \mathrm{dm}^{-3}\right)=0,5 ; \mathrm{P}\left(\mathrm{mg} \mathrm{dm}^{-3}\right)=3,7 ; \mathrm{K}^{+}(\mathrm{mg}$ $\left.\mathrm{dm}^{-3}\right)=126 ; \mathrm{H}^{+}+\mathrm{Al}^{3++}\left(\mathrm{cmolc} \mathrm{dm}^{-3}\right)=2,6 ; \mathrm{Al}$ $\left(\right.$ cmolc dm $\left.\mathrm{dm}^{-3}\right)=0,1 ; \mathrm{SB}\left(\mathrm{cmolc} \mathrm{dm} \mathrm{dm}^{-3}\right)=2,6 ; \mathrm{T}$ $\left.(\mathrm{cmolc} \mathrm{dm})^{-3}\right)=2,7 ; \mathrm{T}\left(\mathrm{cmolc} \mathrm{dm}^{-3}\right)=5,2 ; \mathrm{m}(\%)=$ 4,$0 ; \mathrm{V}(\%)=50$; Matéria orgânica $\left(\right.$ dag $\left.\mathrm{kg}^{-1}\right)=$ 1,5; Areia $\left(\right.$ dag $\left.\mathrm{kg}^{-1}\right)=65$; Silt $\left({\left.\text { dag } \mathrm{kg}^{-1}\right)}^{-1}=20\right.$; Silt $\left(\right.$ Dag $\left.\mathrm{kg}^{-1}\right)=15$. Com base nesses resultados foram realizadas a correção e fertilização do solo.
Como não houve necessiadade de aplicar corretivo no solo, a fertilização foi feita com 300 $\mathrm{kg} \mathrm{ha} \mathrm{h}^{-1}$ da formulação 04-30-10 (N-P-K) no plantio.

A adubação de cobertura foi feita aos 35 dias, usando $60 \mathrm{~kg} \mathrm{ha}^{-1}$ de nitrogênio $(\mathrm{N})$, tendo a ureia como fonte. Foram plantadas 20 sementes e, após o surgimento, as mudas foram diluídas para ajuste do número de plantas por metro linear. A colheita foi realizada em Abril (12/04/2016) e Maio (26/05/2016), totalizando um período experimental de 60 e 80 dias (idade de corte).

Nas duas idades de corte foi ignorada a forragem das bordas ( 1,0 metro) durante a colheita do material para ser ensilado. $O$ milheto foi colhido manualmente e triturado de forma mecanizada utilizando trituradora-picadora elétrica, com facas reguladas para obtenção de partículas de $2 \mathrm{~cm}$. Após trituração e homogeneização de todo o material, cinco montes foram formados e adicionados o aditivo nas respectivas proporções e homogeneizadas antes da ensilagem.

Para ensilagem, foram utilizados silos experimentais de PVC, de pesos conhecidos, com $50 \mathrm{~cm}$ de comprimento e $10 \mathrm{~cm}$ de diâmetro. Após a completa homogeneização da forragem com o aditivo, a mesma foi depositada nos silos e compactada com auxílio de um êmbolo de madeira. Para cada tratamento quantificou-se a densidade da silagem e foi ensilado aproximadamente $3 \mathrm{~kg}$ do material picado de cada forragem fresca, conforme recomendação de Ruppel et al. (1995), com aplicação de densidade de compactação de aproximadamente $500 \mathrm{~kg} \mathrm{~m}^{-3}$ por silo. Após o enchimento, os silos foram fechados com tampas de PVC, dotados de válvula tipo "bunsen", vedados com fita adesiva e pesados em seguida.

Os silos foram armazenados, mantidos à temperatura ambiente, após a ensilagem. Após a abertura com 60 dias, foram coletadas amostras no meio do silo após o descarte da parte superior das silagens que apresentasse presença de fungos.

As amostras foram pré-secas em estufa de ventilação forçada com temperatura de $55^{\circ} \mathrm{C}$ até apresentarem peso constante. Na sequência, o material pré-seco foi moído em moinho tipo "willey" com peneiras de crivo $1 \mathrm{~mm}$ para análise de composição química e $5 \mathrm{~mm}$ para ensaio de digestibilidade e armazenado em potes plásticos, devidamente identificados. 


\section{Revista Agrarian}

Para análises de $\mathrm{pH}$ e nitrogênio amoniacal, foram retiradas amostras da silagem fresca no momento da abertura dos silos. A amostra foi submetida à prensa hidráulica de laboratório, obtendo-se o extrato da silagem com finalidade de determinar o $\mathrm{pH}$, que foi mensurado com um potenciômetro (Wilson e Wilkins, 1972) e o nitrogênio amoniacal, como porcentagem do nitrogênio total $\left(\mathrm{NH}_{3} / \mathrm{NT}\right)$, sendo determinado pelo método da destilação com óxido de magnésio e cloreto de cálcio, usando ácido bórico, como solução receptora e ácido clorídrico a $0,01 \mathrm{~N}$, para titulação segundo metodologia descrita Bolsen et al. (1992).

As amostras após pré-secagem foram analisadas quanto aos teores de matéria seca (MS; 934.01), matéria mineral (cinzas; 942.05), extrato etéreo (EE; 920.39), proteína bruta (PB; 978.04), conforme descrito pela AOAC (1990), e os teores de fibra em detergente neutro (FDN) e fibra em detergente ácido (FDA) pelo método sequencial, conforme procedimentos descritos por Van Soest et al. (1991). A lignina foi mensurada após solubilização da celulose com ácido sulfúrico a $72 \%$, conforme recomendação de Van Soest e Obertson (1985). O teor de carboidrtaos totais (CT) foi estimado pela equação: CT $(\%)=100$ $[\mathrm{PB}+\%$ umidade $(\%)+\mathrm{EE}(\%)+$ cinzas $(\%)]$ e os carboidratos não fibrosos (CNF) de acordo com Sniffen et al. (1992). Os nutrientes digestíveis totais (NDT) foram estimados por meio da fórmula $\mathrm{NDT}=40,2625+0,1969 \mathrm{~PB}+0,4028$ CNF+1,903 EE - 0,1379 FDA (Weiss, 1998). Na Tabela 1, constam os resultados de produção de massa e altura das plantas em cada idade de corte avaliada.

Tabela 1. Dados de produção milheto BRS 1502 em duas idades de corte (dias)

\begin{tabular}{cccc}
\hline Idade de Corte & Matéria Seca (\%) & Produção de Matéria Seca & Altura $(\mathrm{cm})$ \\
\hline 60 & 19,4 & 14,6 & 234 \\
80 & 28,3 & 15,2 & 238 \\
\hline
\end{tabular}

A digestibilidade da matéria seca (DMS) foi estimada após incubação in situ das amostras no rúmen por 264 horas conforme indicado por Casali et al. (2008). A razão entre o resíduo após incubação e amostra inicial multiplicado por 100 foi utilizada para estimar a DMS potencial. A digestibilidade da FDN e PB seguiram as mesmas metodologias citadas.

A glicerina bruta utilizada no experimento apresentou a seguinte composição: teor de matéria seca $(89,5 \%)$, glicerol $(86,9 \%)$, pH $(5,23)$, metanol $(<0,01 \%)$, extrato etéreo $(10,8 \%)$ e proteína bruta $(0,4 \%)$.

Os dados coletados foram submetidos a análise de variância e, quando o teste de " $F$ " foi significativo, as doses de inclusão de glicerina bruta foram analisadas por meio de regressão polinomial utilizando o procedimento REG do SAS, versão 9.2 (SAS Institute Inc., Cary, NC). As idades de corte foram comparadas pelo teste de t. Adotou-se o nível de probabilidade de 5\%. O modelo estatístico utilizado foi o seguinte:

$$
\begin{aligned}
& \text { Yij }=\mu+\mathrm{Ii}+\mathrm{Dj}+\mathrm{Ii} \times \mathrm{Dj}+\mathrm{eij} \\
& \text { Em que: } \\
& \text { Yij= variável dependente; } \\
& \mu=\text { media geral; } \\
& \mathrm{Ii}=\text { efeito da idade de corte }(\mathrm{i}=1 \text { e } 2) \text {; }
\end{aligned}
$$

$$
\text { 3, } 4 \text { e 5); }
$$

$$
\mathrm{Dj}=\text { efeito das doses de glicerina }(\mathrm{j}=1,2 \text {, }
$$$$
\text { Ii } x \mathrm{Dj}=\text { efeito de interação }
$$$$
\text { eij }=\text { erro experimental. }
$$

\section{Resultados e Discussão}

Houve interação entre as idade de corte $\mathrm{x}$ doses de glicerina para as variáveis $\mathrm{pH}$, nitrogênio amoniacal $\left(\mathrm{NH}_{3}\right)$, teor de matéria seca (MS), cinzas, extrato etéreo, fibra em detergente ácido (FDA) e lignina (Tabela 2).

Dentro das doses de 0 e $5 \%$ de glicerina, o $\mathrm{pH}$ da forragem colhida aos 80 dias foi $12,35 \%$ superior à média verificada aos 60 dias (média de $3,72)$. Nas demais doses $(10,15$ e $20 \%)$ o pH não variou entre as idades de colheita, sendo a média de 3,47 . Dentro de cada idade de corte $(60$ e 80 dias), o valor de $\mathrm{pH}$ reduziu linearmente. A redução foi de 0,02 e 0,04 unidades para cada $1 \%$ de inclusão da glicerina na ensilagem de milheto colhido aos 60 e 80 dias, respectivamente (Tabela 3). Em geral, os resultados de pH estão dentro do preconizado para obter perfil fermentativo adequando, o que segundo Moura et al. (2017) está relacionado com a presença de ácido acético e principalmente ácido lático, parâmetros não 


\section{Revista Agrarian}

ISSN: $1984-2538$

estudados nesta pesquisa. Dias et al. (2014) não verificaram efeito da glicerina bruta sobre o $\mathrm{pH}$ de silagem de cana-de-açúcar, comportamento contrário ao verificado neste estudo. A redução do $\mathrm{pH}$ pode ser justificada pela acidez da glicerina e presença de glicerol que é substrato para bactérias homo e heterofermentativa sintetizarem ácidos orgânicos.

A silagem de milheto colhido aos 60 dias apresentou $\quad \mathrm{N}^{-N_{3}} \quad 29,41 \%$ superior em comparação aos 80 dias de colheita. Nas doses de $5 \%$ e $20 \%$ de inclusão de glicerina, o teor de N$\mathrm{NH}_{3}$ não varia entre as idades, sendo média de $4,6 \%$ do NT. Dentro das doses de $10 \%$ e $15 \%$ de glicerina, as maiores médias foram verificadas na idade de 80 dias. Entre as doses de inclusão dentro de cada idade de corte (60 e 80 dias) do milheto, as médias se adequaram ao modelo linear e quadrático de regressão, respectivamente. $\mathrm{Na}$ idade de 60 dias, houve redução de $0,12 \%$ do NT no teor de no $\mathrm{N}_{-} \mathrm{NH}_{3}$ enquanto que na idade de 80 dias, o maior valor para tal variável foi na dose de $14,69 \%$ de glicerina. Os resultados verificados neste estudo estão abaixo dos valores mencionados por Mcdonald et al. (1981). Segundo os mesmos autores, a falta de estabilidade na fermentação da silagem resulta na degradação extensiva de aminoácidos em amônia, $\mathrm{CO}_{2}$ e aminas, incrementando os teores de $\mathrm{N}-\mathrm{NH}_{3}$, o que possivelmente ocorreu na silagem de milheto colhido aos 60 dias.

Para as idades de corte dentro de cada dose de inclusão de glicerina, o teor de MS foi menor com 60 dias em relação aos 80 dias (média de $17,43 \%$ vs $25,26 \%$ ). A inclusão de $20 \%$ de glicerina bruta associada à idade de colheita de 80 dias possibilitou obter silagem de milheto com maior teor de MS, 30,05\%. Isso ocorreu por dois motivos, sendo o primeiro o elevado teor de MS da glicerina $(89,5 \%)$, o que contribuiu com o incremento de $34,84 \%$ no teor de MS. O segundo está relacionado ao efeito da maturidade fisiológica das forrageiras uma vez que, ao aumentar 20 dias na idade de corte do milheto, houve incremento de $31,10 \%$ no teor de MS. À medida que aumenta a idade de corte, ocorrem mudanças na relação conteúdo celular e parede celular, sendo observado aumento nos componentes da parede celular e MS (Velasquez et al., 2010). Com base na revisão de Ferraretto et al. (2018), o aumento na idade de corte promove alterações na produção e valor nutricional da forrageira. Contudo, Row et al. (2016) mencionaram que para a cultura do milho, o teor de MS variando de $29 \%$ a $43 \%$ promove digestibilidade da fibra acima de $60 \%$ da MS, sendo o teor de MS de $32-35 \%$ recomendado como ideal para colheita. Neste estudo, a colheita do milheto com 80 dias e ensilado com 15 e $20 \%$ de inclusão de glicerina promoveu valores próximos do recomendado para milho.

Em relação ao teor de proteína bruta $(\mathrm{PB})$, não houve diferença entre as idades, média de $9,13 \%$ da MS. Contudo, entre as doses de inclusão de glicerina foi verificada redução linear de $0,31 \%$ para unidade de glicerina aplicada. Essa diminuição ocorre devido ao efeito de diluição promovida pelo aditivo. Dias et al. (2014) mencionaram que doses crescentes de inclusão de glicerina na ensilagem de cana-de-açúcar também proporcionam diluição de alguns componentes do conteúdo e da parede celular, fato este observado para os teores de cinzas e proteína bruta (PB) que reduziram linearmente. Em gramíneas, Velasquez et al. (2010) verificaram que o teor de PB pode reduzir com o aumento na idade de corte e neste estudo os teores de PB não diferiram, possivelmente, devido a maior participação de grãos de milheto na maior idade, o que possibilitou a manutenção dos níveis de $\mathrm{PB}$ na ensilagem. Em nutrição de ruminantes, Detmann et al. (2014) relataram a importância de um teor mínimo de PB nas dietas dos animais (em torno de $8 \%$ da MS) para que haja disponibilidade de nitrogênio amoniacal ruminal para os microrganismos degradarem a fração fibrosas da dieta e também sintetizarem proteína microbiana. Desta forma, na inclusão de glicerina em doses acima de $10 \%$ na ensilagem de milheto há necessidade de corrigir o teor de PB com volumosos ou concentrado com elevado teor proteico. 


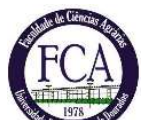

\section{Revista Agrarian}

ISSN: $1984-2538$

Tabela 2. Perfil fermentativo e composição química de silagem de milheto sob níveis de glicerina bruta em duas idades de colheita

\begin{tabular}{|c|c|c|c|c|c|c|c|c|c|c|c|}
\hline \multirow{2}{*}{ Item } & \multirow{2}{*}{$\begin{array}{l}\text { Idade de corte } \\
\quad \text { (dias) }\end{array}$} & \multicolumn{5}{|c|}{ Doses de Glicerina (\% na MN) } & \multirow{2}{*}{ EPM } & \multicolumn{4}{|c|}{ P-Valor } \\
\hline & & 0 & 5 & 10 & 15 & 20 & & I & D x I & D Linear & D Quadr \\
\hline \multirow{2}{*}{$\mathrm{pH}$} & 60 & $3,86 \mathrm{~B}$ & $3,59 \mathrm{~B}$ & $3,53 \mathrm{~A}$ & $3,44 \mathrm{~A}$ & $3,36 \mathrm{~A}$ & \multirow{2}{*}{0,01} & \multirow{2}{*}{$<0,01$} & \multirow{2}{*}{0,02} & \multirow{2}{*}{0,02} & \multirow{2}{*}{0,69} \\
\hline & 80 & $4,16 \mathrm{~A}$ & $4,34 \mathrm{~A}$ & $3,50 \mathrm{~A}$ & $3,53 \mathrm{~A}$ & $3,46 \mathrm{~A}$ & & & & & \\
\hline \multirow{2}{*}{$\mathrm{N}-\mathrm{NH}_{3}, \% \mathrm{NT}$} & 60 & $7,14 \mathrm{~A}$ & $4,80 \mathrm{~A}$ & $4,17 \mathrm{~B}$ & $4,17 \mathrm{~B}$ & $4,24 \mathrm{~A}$ & \multirow{2}{*}{0,21} & \multirow{2}{*}{0,61} & \multirow{2}{*}{$<0,01$} & \multirow{2}{*}{$<0,01$} & \multirow{2}{*}{0,02} \\
\hline & 80 & $5,04 \mathrm{~B}$ & $4,97 \mathrm{~A}$ & $5,18 \mathrm{~A}$ & $5,32 \mathrm{~A}$ & $4,48 \mathrm{~A}$ & & & & & \\
\hline \multirow{2}{*}{ Matéria seca, \% } & 60 & $10,55 \mathrm{~B}$ & $11,80 \mathrm{~B}$ & $14,48 \mathrm{~B}$ & $23,83 \mathrm{~B}$ & $26,49 \mathrm{~B}$ & \multirow{2}{*}{0,50} & \multirow{2}{*}{$<0,01$} & \multirow{2}{*}{$<0,01$} & \multirow{2}{*}{$<0,01$} & \multirow{2}{*}{0,01} \\
\hline & 80 & $19,58 \mathrm{~A}$ & $23,21 \mathrm{~A}$ & $24,88 \mathrm{~A}$ & $28,61 \mathrm{~A}$ & $30,05 \mathrm{~A}$ & & & & & \\
\hline \multirow{2}{*}{ Cinzas, \% } & 60 & $9,55 \mathrm{~B}$ & $9,15 \mathrm{~A}$ & $8,70 \mathrm{~A}$ & $8,47 \mathrm{~A}$ & $8,43 \mathrm{~A}$ & \multirow{2}{*}{0,20} & \multirow{2}{*}{0,04} & \multirow{2}{*}{0,01} & \multirow{2}{*}{$<0,01$} & \multirow{2}{*}{$<0,01$} \\
\hline & 80 & $10,87 \mathrm{~A}$ & $9,04 \mathrm{~A}$ & $8,80 \mathrm{~A}$ & 7,71 B & $8,44 \mathrm{~A}$ & & & & & \\
\hline \multirow{2}{*}{ Proteína bruta, \% } & 60 & 11,83 & 11,27 & 9,47 & 7,05 & 6,19 & 0 & 0.6 & 025 & $<001$ & 063 \\
\hline & 80 & 12,79 & 10,34 & 9,09 & 7,16 & 6,20 & 0,4 & 0,86 & 0,20 & $<0,01$ & 0,63 \\
\hline Evtrotentéroo 0 & 60 & $2,98 \mathrm{~A}$ & $4,02 \mathrm{~A}$ & $4,30 \mathrm{~B}$ & $4,42 \mathrm{~B}$ & 7,39 B & 02 & $<0 \Omega 1$ & $<001$ & $<0 \Omega 1$ & $<0 \Omega 1$ \\
\hline Extrato etereo, \% & 80 & $3,52 \mathrm{~A}$ & $4,33 \mathrm{~A}$ & $6,09 \mathrm{~A}$ & $7,40 \mathrm{~A}$ & $9,69 \mathrm{~A}$ & 0,3 & $<0,01$ & $<0,01$ & $<0,01$ & $<0,01$ \\
\hline EDN 0 & 60 & 55,96 & 48,94 & 43,66 & 37,07 & 34,87 & 100 & 001 & 060 & $<0 \Omega 1$ & 016 \\
\hline FDN, $\%$ & 80 & 58,09 & 53,31 & 45,40 & 40,16 & 35,24 & 1,00 & 0,01 & 0,69 & $<0,01$ & 0,16 \\
\hline FDNen 0 & 60 & 45,26 & 37,00 & 32,86 & 28,83 & 27,95 & 100 & 008 & 066 & $<0 \Omega 1$ & 008 \\
\hline FDNCp, $\%$ & 80 & 45,97 & 42,31 & 33,29 & 34,22 & 29,14 & 1,00 & 0,08 & 0,06 & $<0,01$ & 0,08 \\
\hline EDA 0 & 60 & $36,66 \mathrm{~A}$ & $30,03 \mathrm{~A}$ & $28,00 \mathrm{~A}$ & $32,07 \mathrm{~A}$ & $27,68 \mathrm{~A}$ & 000 & $<001$ & $<001$ & $<001$ & 014 \\
\hline FDA, $\%$ & 80 & $34,99 \mathrm{~A}$ & $30,96 \mathrm{~A}$ & $28,40 \mathrm{~A}$ & $22,98 \mathrm{~B}$ & 20,42 B & 0,90 & $<0,01$ & $<0,01$ & $<0,01$ & 0,14 \\
\hline I inang 0 & 60 & $6,16 \mathrm{~A}$ & $7,03 \mathrm{~A}$ & $5,88 \mathrm{~A}$ & $6,77 \mathrm{~A}$ & $5,18 \mathrm{~A}$ & 015 & $<001$ & 002 & 006 & 010 \\
\hline Lignina, \% & 80 & $5,16 \mathrm{~A}$ & $4,29 \mathrm{~B}$ & $4,53 \mathrm{~B}$ & $4,57 \mathrm{~B}$ & $4,59 \mathrm{~A}$ & 0,15 & $<0,01$ & 0,03 & 0,06 & 0,49 \\
\hline Corbiduoto to o & 60 & 76,18 & 79,51 & 80,73 & 83,17 & 84,53 & 060 & 007 & 0.57 & -001 & 002 \\
\hline Carboraratos totais, \% & 80 & 73,88 & 78,73 & 79,81 & 83,39 & 83,82 & 0,00 & 0,07 & $0,3 /$ & $<0,01$ & 0,03 \\
\hline$C N E=0$ & 60 & 30,92 & 42,50 & 47,86 & 54,34 & 56,58 & 170 & 003 & 082 & $<001$ & 000 \\
\hline$C N \Gamma, 70$ & 80 & 27,91 & 36,42 & 46,52 & 49,16 & 54,69 & 1,10 & $0,0 S$ & 0,02 & $-0,01$ & 0,02 \\
\hline
\end{tabular}

Médias seguidas de mesma letra na coluna não diferem entre si pelo teste de t à $5 \%$ de probabilidade. $\mathrm{pH}$ - Potencial de Hidrogênio; $\mathrm{N}-\mathrm{NH}_{3}$ - Nitrogênio amoniacal; NT - Nitrogênio total; NIDN Nitrogênio insolúvel em detergente neutro; FDN - Fibra em detergente neutro; FDNcp - Fibra em detergente neutro corrigido para cinzas e proteínas; FDA - Fibra em detergente ácido; CT -

Carboidratos totais; CNF - Carboidratos não fibrosos; MN - Matéria natural; EPM - erro padrão da média; I - idade de corte; D - Doses de glicerina; I x D -interação 


\section{Revista Agrarian}

ISSN: $1984-2538$

Tabela 3. Equações de regressão de variáveis do perfil fermentativo e valor nutricional de silagem de milheto

\begin{tabular}{|c|c|c|c|}
\hline Item & Idade de corte & Equação de Regressão & $\mathrm{R}^{2}$ \\
\hline \multirow{2}{*}{$\mathrm{pH}$} & 60 & $\hat{\mathrm{Y}}=-0,0227^{*} \mathrm{X}+3,783$ & 0,90 \\
\hline & 80 & $\hat{\mathrm{Y}}=-0,0442 * \mathrm{X}+4,2398$ & 0,70 \\
\hline \multirow{2}{*}{$\mathrm{N}-\mathrm{NH}_{3}, \% \mathrm{NT}$} & 60 & $\hat{\mathrm{Y}}=-0,1288 \mathrm{X}+6,188$ & 0,63 \\
\hline & 80 & $\hat{Y}=0,0156 * X^{2}-0,4408 * X+6,968$ & 0,95 \\
\hline \multirow{2}{*}{ Matéria seca, \% } & 60 & $\hat{Y}=-0,0046 * X^{2}+0,0766 X+4,922$ & 0,60 \\
\hline & 80 & $\hat{\mathrm{Y}}=0,8779 * \mathrm{X}+8,6496$ & 0,91 \\
\hline \multirow{2}{*}{ Cinzas, $\%$} & 60 & $\hat{Y}=-0,0587 * X+9,4477$ & 0,91 \\
\hline & 80 & $\hat{Y}=-0,1237 * X+10,211$ & 0,70 \\
\hline Proteína bruta, \% & $\begin{array}{l}60 \\
80\end{array}$ & $\hat{Y}=-0,3186 X+12,325$ & 0,98 \\
\hline \multirow{2}{*}{ Extrato etéreo, \% } & 60 & $\hat{Y}=0,1844 * X+2,7772$ & 0,78 \\
\hline & 80 & $\hat{\mathrm{Y}}=0,3083 * \mathrm{X}+3,1246$ & 0,97 \\
\hline FDN, $\%$ & $\begin{array}{l}60 \\
80\end{array}$ & $\hat{Y}=-1,129 * X+56,559$ & 0,99 \\
\hline FDNcp, $\%$ & $\begin{array}{l}60 \\
80\end{array}$ & $\hat{Y}=-0,8456 * X+44,139$ & 0,94 \\
\hline \multirow{2}{*}{ FDA, $\%$} & 60 & $\hat{Y}=-0,3187 X+34,076$ & 0,47 \\
\hline & 80 & $\hat{Y}=-0,7423^{*} X+34,973$ & 0,98 \\
\hline \multirow{2}{*}{ Lignina, \% } & 60 & $\hat{Y}=-0,0441 X+6,6449$ & 0,22 \\
\hline & 80 & $\hat{Y}=-0,017 X+4,7996$ & 0,17 \\
\hline Carboidratos totais, $\%$ & $\begin{array}{l}60 \\
80\end{array}$ & $\hat{Y}=0,4490 * X+75,88$ & 0,95 \\
\hline \multirow{2}{*}{$\mathrm{CNF}, \%$} & 60 & $\hat{Y}=12946 * X+3174$ & 095 \\
\hline & 80 & $Y=1,2940^{*} X+31, / 4$ & 0,95 \\
\hline
\end{tabular}

pH - Potencial de Hidrogênio; N-NH 3 - Nitrogênio amoniacal; NT - Nitrogênio total; NIDN - Nitrogênio insolúvel em detergente neutro; FDN - Fibra em detergente neutro; FDNcp - Fibra em detergente neutro corrigido para cinzas e proteínas; FDA - Fibra em detergente ácido; CT - Carboidratos totais; CNF - Carboidratos não fibrosos; $\mathrm{R}^{2}$ - Coeficiente de variação. * significativo pelo teste de t, à $5 \%$ de probabilidade

Sobre os teores de EE entre as idades de corte dentro de cada dose de inclusão de glicerina, foi verificado que não houve diferença dentro das doses 0 e $5 \%$, sendo média de $3,71 \%$. A forragem colhida aos 80 dias apresentou maior teor de EE dentro das doses de 10,15 e $20 \%$ em relação à idade de 60 dias. Dentro das idades de corte, verificou-se que a inclusão de glicerina aumentou linearmente o teor de EE. Esse incremento é justificável devido o alto teor de EE (10,5\%) presente na glicerina. É valido destacar que o uso de silagem de milheto aditivada com $20 \%$ de glicerina quando utilizada como dieta completa para ruminantes, além do teor de PB limitante, o elevado teor de EE, 9,69\%, pode contribuir na redução da ingestão de MS pelo animal conforme verificado por Lage et al. (2010). Em ruminantes, a ingestão de nutrientes pode reduzir quando doses de EE da dieta excedem $8 \%$ da MS, o que possibilita inferir que esses animais são relativamente intolerantes a altos níveis de lipídeos (Palmquist e Jankins, 1980). Vários fatores podem afetar a ingestão de MS como o tamanho e frequência da refeição, que são determinadas pelo animal e fatores intrínsecos à dieta que afetam o apetite e a saciedade (Lage et al., 2010). Dessa forma, a silagem de milheto aditivada com até $15 \%$ de glicerina está dentro dos limitantes para que não haja redução no consumo.

Para os teores de FDA e Lignina, houve redução linear com o incremento das doses de glicerina nas idades de corte. Entre as idades, os maiores valores de FDA foram verificados na dose de $15 \%$ e $20 \%$ com a forragem colhida aos 60 dias. Quanto os teores de lignina, as maiores 


\section{(ㄱ)}

\section{Revista Agrarian}

ISSN: $1984-2538$

médias também foram verificadas no milheto colhido aos 60 dias nas doses de 5, 10 e $15 \%$ de inclusão da glicerina.

Os teores de fibra em detergente neutro (FDN) e fibra em detergente neutro corrigida para cinzas e proteína aumentaram 5,2\% e 7,6 unidades percentuais quando incrementou a idade de corte de 60 para 80 dias, respectivamente. Esses resultados contribuíram para elevar o teor de MS e estão relacionados com as alterações na proporção dos constituintes celulares. Entre as doses, os teores de FDN e FDNcp ajustaram-se ao modelo linear decrescente de regressão, sendo justificado pelo efeito de diluição proporcionado pela inclusão de glicerina na ensilagem.

A inclusão de 5, 10, 15 e 20\% de glicerina bruta na ensilagem de milheto incrementou linearmente $0,44 \%$ para $1 \%$ de inclusão da glicerina sobre os teores de carboidratos totais (CT). Entre as idades de corte não houve diferença sobre os CT, com média de $80,37 \%$ $(P=0.07)$. Os teores de carboidratos não fibrosos (CNF) aumentaram linearmente com a inclusão de glicerina. Entre as idades, a colheita antecipada aos 60 dias elevou o teor de CNF em 8,1\% em relação aos 80 dias $(42,9 \%)$.

Houve interação entre as doses de glicerina e idade de rebrota sobre os teores de nutrientes digestíveis totais (NDT; $\mathrm{P}=0,01)$. As maiores médias foram verificadas nas doses de $15 \%$ e $20 \%$ quando o milheto foi colhido com 80 dias em relação aos 60 dias. Dentro das idades de corte, as médias aumentaram linearmente $0,84 \%$ (60 dias) e 1,15\% (80 dias) para cada unidade percentual de inclusão da glicerina durante a ensilagem (Tabela 4).

$\mathrm{O}$ teor de glicerol de $86,9 \%$ associado com o EE é o principal responsável pelo incremento no teor de energia da silagem, o que é interessante quando se pretende reduzir os custos de produção com a menor inclusão de ingredientes concentrados ricos em energia de elevado valor de aquisição. Nas regiões semiáridas do Brasil, onde a disponibilidade de glicerina bruta devido à concentração de indústrias produtora de biodiesel, é elevada, relacionado ao custo de insumos convencionais como o milho, sorgo e farelo de trigo, por exemplo, é muito interessante quando se pretende aumentar a densidade energética da dieta. Além disso, o uso de glicerina bruta em dietas para ruminantes evita o descarte incorreto desses subprodutos (San Vito et al., 2016).

A relação proteína bruta: NDT não foi alterada nos diferentes tratamentos $(\mathrm{P}=0.28)$, sendo a média de 0,143 . Não houve interação entre as idades de corte e doses de glicerina sobre a digestibilidade da MS $(\mathrm{P}=0,42)$ e digestibilidade da FDN $(\mathrm{P}=0,80)$. Em relação à silagem controle $(63,4 \%)$, a digestibilidade MS incrementou $10 \%, \quad 16,9 \%, 23,9 \%$ e $26,2 \%$ respectivamente, nas doses de $5,10,15$ e $20 \%$. Além disso, a planta de milheto colhida aos 60 dias apresentou digestibilidade da MS e FDN $12,9 \%$ e $30,4 \%$ superior em relação aos 80 dias, respectivamente. A ensilagem da planta de milheto aos 60 dias de idade sem aditivo apresentou maior digestibilidade da PB (55,9\%) em relação aos demais tratamentos.

\section{Conclusão}

A colheita da planta de milheto aos 80 dias associada com a utilização de $15 \%$ glicerina bruta na matéria natural durante a ensilagem melhora o perfil fermentativo e as características nutricionais da silagem.

\section{Agradecimentos}

Os autores agradecem a Universidade Estadual de Montes Claros, e Embrapa Milho e Sorgo pelo suporte financeiro e Fundação de Amparo à Pesquisa do Estado de Minas Gerais e Conselho Nacional de Desenvolvimento Tecnológico e Científico concessão de bolsas de estudos.

O presente trabalho foi realizado com apoio da Coordenação de Aperfeiçoamento de Pessoal de Nível Superior - Brasil (CAPES) Código de Financiamento 001. 


\section{Revista Agrarian \\ ISSN: $1984-2538$}

Tabela 4. Valor nutricional de silagem de milheto colhido em duas idades de corte sob níveis de glicerina bruta

\begin{tabular}{|c|c|c|c|c|c|c|c|c|c|c|c|}
\hline \multirow{2}{*}{ Item $(\%)$} & \multirow{2}{*}{$\begin{array}{c}\text { Idade de } \\
\text { corte } \\
\text { (dias) }\end{array}$} & \multicolumn{5}{|c|}{ Doses de Glicerina (\% na MN) } & \multirow{2}{*}{ EPM } & \multicolumn{4}{|c|}{ P-Valor } \\
\hline & & 0 & 5 & 10 & 15 & 20 & & $\mathrm{I}$ & $\mathrm{D} \times \mathrm{I}$ & D Linear & D Quadr \\
\hline \multirow{2}{*}{$\begin{array}{l}\text { Nutrientes digestíveis } \\
\text { totais }^{1}\end{array}$} & 60 & $55,66 \mathrm{~A}$ & $63,11 \mathrm{~A}$ & $65,73 \mathrm{~A}$ & $67,53 \mathrm{~B}$ & $74,51 \mathrm{~B}$ & \multirow{2}{*}{0,80} & \multirow{2}{*}{0,01} & \multirow{2}{*}{0,01} & \multirow{2}{*}{$<0,01$} & \multirow{2}{*}{0,73} \\
\hline & 80 & $55,90 \mathrm{~A}$ & $60,94 \mathrm{~A}$ & $68,46 \mathrm{~A}$ & $72,39 \mathrm{~A}$ & $79,14 \mathrm{~A}$ & & & & & \\
\hline \multirow{2}{*}{ Relação PB_NDT ${ }^{2}$} & 60 & 0,21 & 0,18 & 0,14 & 0,10 & 0,08 & \multirow{2}{*}{0,01} & \multirow{2}{*}{0,54} & \multirow{2}{*}{0,28} & \multirow{2}{*}{$<0,01$} & \multirow{2}{*}{0,01} \\
\hline & 80 & 0,23 & 0,17 & 0,13 & 0,10 & 0,08 & & & & & \\
\hline \multirow{2}{*}{$\begin{array}{l}\text { Digestibilidade da } \\
\text { matéria seca }^{3}\end{array}$} & 60 & 71,14 & 77,75 & 77,37 & 80,41 & 81,47 & \multirow{2}{*}{3,2} & \multirow{2}{*}{$<0,01$} & \multirow{2}{*}{0,42} & \multirow{2}{*}{$<0,01$} & \multirow{2}{*}{0,43} \\
\hline & 80 & 55,68 & 61,69 & 70,74 & 76,69 & 78,52 & & & & & \\
\hline \multirow{2}{*}{$\begin{array}{l}\text { Digestibilidade da } \\
\text { proteína bruta }^{4}\end{array}$} & 60 & 49,41 & 57,64 & 48,055 & 32,49 & 18,86 & \multirow{2}{*}{2,1} & \multirow{2}{*}{0,72} & \multirow{2}{*}{0,12} & \multirow{2}{*}{$<0,01$} & \multirow{2}{*}{$<0,01$} \\
\hline & 80 & 62,37 & 46,52 & 40,87 & 33,15 & 18,37 & & & & & \\
\hline \multirow{2}{*}{$\begin{array}{l}\text { Digestibilidade da fibra } \\
\text { em detergente neutro }\end{array}$} & 60 & 52,4 & 58,2 & 52,52 & 51,36 & 57,51 & \multirow{2}{*}{6,2} & \multirow{2}{*}{0,03} & \multirow{2}{*}{0,80} & \multirow{2}{*}{0,22} & \multirow{2}{*}{0,87} \\
\hline & 80 & 30,94 & 37,13 & 45,46 & 45,48 & 49,49 & & & & & \\
\hline
\end{tabular}

PB NDT - Relação proteína bruta energia; EPM - Erro padrão da média; I - idade de corte; D - Doses de glicerina; I x D -interação ${ }^{1} \hat{\mathrm{Y}} 60$ dias $=0,8426 * \mathrm{X}+56,883, \mathrm{R}^{2}=0,94 ;{ }^{1} \hat{\mathrm{Y}}{ }_{80}$ dias $=1,1587 * \mathrm{X}+$ $55, \overline{7} 81, \mathrm{R}^{2}=0,99 ;{ }^{2} \hat{\mathrm{Y}}=-0,007 * \mathrm{X}+0,2137, \mathrm{R}^{2}=0,98 ;{ }^{3} \hat{\mathrm{Y}}=0,84 * \mathrm{X}+64,746, \mathrm{R}^{2}=0,96 ;{ }^{4} \hat{\mathrm{Y}}=-1,8762 * \mathrm{X}+59,536, \mathrm{R}^{2}=0,95 ;{ }^{5} \hat{\mathrm{Y}}=0,4883 * \mathrm{X}+43,166, \mathrm{R}^{2}=0,83 .{ }^{*}$ significativo pelo teste de $\mathrm{T}$, a $5 \%$ 


\section{Referências}

AOAC, Official Methods of Analysis of AOAC International, 16 ed. Association of Official Analytical Chemists, Arlington, 1995.

BOLSEN, K. K.; LIN, C.; BRENT, B. E. Effect of silage additives on the microbial succession and fermentation process of alfalfa and corn silages. Journal of Dairy Science, v. 75, n. 1, p.3066-3083, 1992.

CAMPOS, F. S.; CARVALHO, G. G. P.; SANTOS, E. M.; ARAÚJO, G. G. L; GOIS, G. C.; REBOUÇAS, R. A.; LEÃO, A. G.; SANTOS, S. A.; OLIVEIRA, J. S.; LEITE, L. C.; ARAÚJO, M. L. G. M. L.; CIRNE, L. G. A.; SILA, R. R.; CARVALHO, B. M. A. Influence of diets with silage from forage plants adapted to the semi-arid conditions on lamb quality and sensory attributes. Meat Science, v. 24, n.1, p.61-68.

CASALI, A. O.; DETMANN, E.; VALADARES FILHO, S. C.; PEREIRA, J. C.; HENRIQUES, L. T.; FREITAS, S. G.; PAULINO, M. F. Influência do tempo de incubação e do tamanho de partículas sobre os teores de compostos indigestíveis em alimentos e fezes bovinas obtidos por procedimentos in situ. Revista Brasileira de Zootecnia, v.37, n.2, p.335-342, 2008.

CHANJULA, P.; PAKDEECHANUAN, P.; WATTANASIT, S. Effects of dietary crude glycerin supplementation on nutrient digestibility, ruminal fermentation, blood metabolites, and nitrogen balance of goats. Asian Australas Journal Animal Science, Seoul, v. 27, n. 3, p. 365-374, 2014.

DIAS, A.M.; ÍTAVO, L.C.V.; ÍTAVO, C.C.B.F.; BLAN, L.R.; GOMES, E.N.O.; SOARES, C.M.; LEAL, E.S.; NOGUEIRA, COELHO, E.M. Ureia e glicerina bruta como aditivos na ensilagem de cana-de-açúcar. Arquivo Brasileiro de Medicina Veterinária e Zootecnia, v.66, n.1, p.1874-1882, 2014.

DETMANN, E.; VALENTE, E. E. L.; HUHTANEN, P. An evaluation of the performance and efficiency of nitrogen utilization in cattle fed tropical grass pastures with supplementation. Livestock Science, v.162, n.1, p.141-153, 2014.

FERRARETTO, L.F.; SHAVER, R.D.; LUCK, B.D. Silage review: Recent advances and future technologies for whole-plant and fractionated corn silage harvesting. Journal of Dairy Science, v. 101, p.3937-3951, 2018.

KERR, B. J.; WEBER, T. E.; DOZI, W. A.; KIDD, M. T. Digestible and metabolizable energy content of crude glycerin originating from different sources in nursery pigs. Journal of Animal Science, v. 87, p. 4042-4049, 2009.

MCDONALD, P.; HENDERSON, A. R.; HERON, S. J. E. The biochemistry of silage. 2th ed. Marlow: Chalcomb Publisher, 1991. 340 p.

LAGE, J. F.; PAULINO, P. V. R.; PEREIRA, L. G. R.; VALADARES FILHO, S. C.; OLIVEIRA, A. S.; DETMANN, E.; SOUZA, N. K. P.; Glicerina bruta na dieta de cordeiros terminados em confinamento. Pesquisa Agropecúaria Brasileira, v.45, n.9, p.1012-1020, 2010.

LEE, S. Y.; LEE, S. M.; CHO, Y. B.; KAM, D. K.; LEE, S. C., KIM, S. H.; SEO, S. Glycerol as a feed supplement for ruminants: In vitro fermentation characteristics and methane production. Animal Feed Science and Technology, v.166-167, p. 269-274, 2011.

MOURA, M. M. A.; PIRES, D. A. A.; COSTA, R. F.; TOLENTINO, D. C.; RIGUEIRA, J. P. S.; SALES, E. C. J. Nutritional value of sorghum silages. Acta Scientarium Animal Sciences, v. 39, n. 1, p. 137-142, 2017.

NUNES, A. T.; CABRAL, D. L. V.; AMORIM, E. L. C.; SANTOS, M. V. F.; ALBUQUERQUE, U. P. Plants used to feed ruminants in semi-arid Brazil: A study of nutritional composition guided by local ecological knowledge. Journal of Arid Environments, v.135, n.1, p.96-103, 2016.

OLIVEIRA FILHO, C. A. A.; AZEVÊDO, J. A. G.; CARVALHO, G. G. P.; SILVA, C. F. P. G.; CABRAL, I. S.; PEREIRA, L. G. R.; REIS, L. G.; ALMEIDA, F. M.; SOUZA, L. L. Crude glycerin combined with sugar cane silage in lamb 
diets.Tropical Animal health and production, v.48, n.2, p.289-295, 2016.

PAIVA, P. G.; DEL VALLE, T. A.; JESUS, E. F.; BETTERO, V. P.; ALMEIDA, G. F.; BUENO, I. C. S.; BRADFORD, B. J.; RENNÓ, F. P. Effects of crude glycerin on milk composition, nutrient digestibility and ruminal fermentation of dairy cows fed corn silage-based diets. Animal Feed Science and Technology, v.212, n.1, p.136-142, 2016.

PALMQUIST, D. L., JENKINS, T. C. Fat in lactation rations: review. Journal of Dairy Science, v.63, n.1, p.1-14, 1980.

RUPPEL, K. A.; PITT, R. E.; CHASE, L. E.; GALTON, D. M. Bunker silo management and its relationship to forage preservation on dairy farms. Journal of Dairy Science, v. 78, n. 1, p. 141-153, 1995.

ROW, C. A., R. G. BONDURANT, A. K. WATSON, J. L. HARDING, J. C. MACDONALD, T. J. KLOPFENSTEIN, AND G. E. ERICKSON. 2016. Effect of corn plant maturity on yield and nutrient quality of corn plants, 2-year summary. Nebraska Beef Cattle Rep. MP103: 79-80. University of Nebraska, Lincoln.

SAN VITO, E.; MESSANA, J. D.; CASTAGNINO, P. S.; GRANJA-SALCEDO, Y. T.; DALLANTONIA, E. E.; BERCHIELLI, T. T. Effect of crude glycerine in supplementon the intake, rumen fermentation, and microbial profile of Nellore steers grazing tropical grass. Livestock Science, v.192, p.17-24, 2016.

SNIFFEN, C. J.; O`CONNOR, J. D.; VAN SOEST, P.J. A net carboidrate and protein system for evaluating cattle diets. II. Carboidrate and protein availability. Journal of Animal Science, v.70, n.11, p.3562-3577, 1992.

VAN SOEST, P.J.; ROBERTSON, J.B.; LEWIS, B.A. Methods for dietary À ber neutral detergent and nonstarch polysaccharides in relation to animal nutrition. Journal of Dairy Science, v. 74, p. 3583-3597, 1991.
VELÁSQUEZ, P.A.T.; BERCHIELLI, T.T.; REIS, R.A.; RIVERA, A.R.; DIAN, P.H.M.; TEIXEIRA, I. A.M.A. Composição química, fracionamento de carboidratos e proteínas e digestibilidade in vitro de forrageiras tropicais em diferentes idades de corte. Revista Brasileira de Zootecnia, v.39, n.6, p.1206-1213, 2010.

WEISS, W.P. Estimating the available energy content of feeds for dairy cattle. Journal of Dairy Science, v.81, p. 830-839, 1998.

WILSON, R. F; WILKINS, R. J. An evaluation of laboratory ensiling techniques. Journal of Science of Food and Agricultural, v. 23, n.1, p. 377-382, 1972. 